\title{
Effect of Short- and Long-Term High-Fat Feeding on Autophagy Flux and Lysosomal Activity in Rat Liver
}

\author{
Z. PAPÁČKOVÁ ${ }^{1}$, H. DAŇKOVÁ ${ }^{1}$, E. PÁLENÍČKOVÁ ${ }^{1}$, L. KAZDOVÁ $^{1}$, M. CAHOVÁ ${ }^{1}$ \\ ${ }^{1}$ Department of Metabolism and Diabetes, Institute for Clinical and Experimental Medicine, Prague, \\ Czech Republic
}

Received March 19, 2012

Accepted May 24, 2012

\begin{abstract}
Summary
Autophagy-lysosomal pathway is a cellular mechanism ensuring degradation of various macromolecules like proteins or triacylglycerols (TAG). Its disruption is related to many pathological states, including liver steatosis. We compared the effect of short- and long-established steatosis on the intensity of autophagy-lysosomal pathway in rat liver. The experiments were carried out on 3-month old Wistar rats fed standard (SD) or highfat diet for 2 (HF-2) or 10 (HF-10) weeks. HF diet administered animals accumulated an increased amount of TAG in the liver (HF-2 $\rightarrow \mathrm{HF}-10)$. Autophagy flux was up-regulated in HF-2 group but nearly inhibited after 10 weeks of HF administration. The expression of autophagy related genes was up-regulated in HF-2 but normal in HF-10. In contrast, total activities of two lysosomal enzymes, lysosomal lipase (LAL) and acid phosphatase, were unaffected in HF-2 but significantly increased in HF-10 groups. mRNA expression of lysosomal enzymes was not affected by the diet. We conclude that in a state of metabolic unbalance (steatosis), autophagy machinery and lysosomal enzymes expression are regulated independently. The accumulation of TAG in the liver is associated with the increase of total LAL activity and protein expression. In contrast, the autophagy response is bi-phasic and after rapid increase it is significantly diminished. This may represent an adaptive mechanism that counteracts the excessive degradation of substrate, i.e. TAG, and eliminate over-production of potentially hazardous lipiddegradation intermediates.
\end{abstract}

\section{Key words}

Autophagy $\bullet$ Lysosomal $\bullet$ Liver $\bullet$ Lysosomal lipase $\bullet$ Biolysis

\section{Corresponding author}

Zuzana Papackova, Institute for Clinical and Experimental Medicine, Department of Metabolism and Diabetes, Videnska
1958/9, 14021 Prague 4, Czech Republic. Fax: +420261363027. E-mail: zuzana.papackova@ikem.cz

\section{Introduction}

Autophagy-lysosomal pathway is essential for the maintenance of cellular and metabolic homeostasis. Following nutrient deprivation, the primary cellular response is the induction of autophagy that breaks down redundant cellular components and provides amino acids and additional precursor molecules for processes critical for cellular survival (Singh 2010). For a long time, autophagy was mostly associated with degradation of proteins. Only recently, Singh et al. (2009) showed that lipid droplets in hepatocytes can enter the autophagic degradation pathway in the same manner as damaged proteins or organelles via formation of autophago(lipo)somes that carry the cargo to the final degradation in lysosomes.

The autophagy-lysosomal pathway consists of two different, but functionally interconnected, parts. Autophagy (autophagocytosis) starts with the engulfing or sequestration of a part of the cytoplasm by a specialised membranous organelle called a phagophore (Seglen 1987). The resulting autophagosome matures into or delivers the sequestered cytoplasm to an amphisome, a collecting vacuole that can also receive material from endocytosis (Gordon et al. 1992). Amphisome in turn delivers its content to a lysosome, resulting in exposure of the autophagocytosed cytoplasm to the hydrolytic enzymes of the lysosomes. Lysosomes are permanently present in the cell and formed in the Golgi complex. They contain various hydrolytic enzymes capable of digesting an array of biological polymers, including proteins, nucleic acids, 
carbohydrates and lipids (De Duve and Wattiaux 1966).

Autophagy is a complex process that involves the participation of at least 30 proteins (Suzuki et al. 2007). These proteins can be divided into 3 functional groups (Levine and Kroemer 2008). The first group are serin/threonine kinases like ATG1 and mTOR that sense the external nutrient environment and initiate the autophagy process (Jung et al. 2009). Next, parts of cytoplasm containing material for degradation are engulfed by simple membrane forming phagophore containing a protein complex carrying Beclin 1 and PI3K activity. This complex modifies the nascent autophagosomal membrane (Cao and Klionsky 2007) and the cargo is sequestered in a double membrane structure called autophagosome. During this step a protein called ATG8/LC3-II is inserted into both sides of the autophagosomal membrane and serves as a convenient marker for this structure (Klionsky et al. 2008). After formation of autophagosome, the outer membrane fuses with lysosomes while the inner membranes and sequestered contents are subsequently digested by lysosomal hydrolases within the lysosomal lumen (Jager et al. 2004).

Mounting evidence has demonstrated that disruption of the physiological function of autophagy is strongly related to human diseases, including neurodegeneration, cancer, liver and heart diseases, ageing, myopathies, and infection (Mizushima et al. 2008). The newly described interrelationship between autophagy and lipid metabolism suggests that alteration in autophagic function may play a role in the pathophysiology of human disorders that result from excessive cellular lipid accumulation, such as liver steatosis. Autophagy and lipolysis share striking similarities. Both are essential catabolic pathways activated in response to nutrient deprivation. They are under identical hormonal control, being activated by glucagon and inhibited by insulin (Finn and Dice 2006). The main objection given against autophagy involvement in the degradation of intracellular lipid droplets was different intracellular localisation of lipolytic enzyme (lysosomal lipase sequestered in lysosomes) and substrate (lipid droplets in cytoplasm). Only recently, Singh et al. (2009) brought evidence supporting the hypothesis that lipid droplets in hepatocytes can enter the autophagic degradation pathway in the same manner as damaged proteins or organelles via formation of autophago(lipo)somes that carry the cargo to the final degradation in lysosomes. Further evidence for the role of autophagy in hepatocyte lipid metabolism came from experiments carried out on mice with a hepatocyte-specific knockout of the autophagy gene atg7 that developed a massively enlarged liver. The enlargement was partly caused by markedly increased in triacylglycerol and cholesterol content and decreased VLDL secretion. These findings suggest that a general impairment in autophagy or a specific defect in lipophagy might in part underlie the development of steatotic liver diseases such as nonalcoholic fatty liver disease but the causal relationship remains to be verified.

The aim of our study was to address the issue concerning the effect of the duration steatosis-promoting high-fat diet on the intensity of autophagy-lysosomal pathway in the rat liver. We particularly focused on the regulation of autophagy flux and on the lysosomal activity at the functional (autophagy flux measurements in vivo, determination of lysosomal enzymes activities) and transcriptional (determination of mRNA expression) levels.

\section{Material and Methods}

\section{Animal and experimental protocol}

Male Wistar rats were kept in temperaturecontrolled room at 12:12-h light-dark cycle. The animals had free access to drinking water and standard chow-diet if not stated otherwise. Starting at the age of 3 months, the rats were fed with standard (SD, 25 w.w. \% protein, 4 w.w. $\%$ fat, 68 w.w. $\%$ starch) or high-fat (HF, 14 w.w. $\%$, protein, 33 w.w. $\%$ fat, 20 w.w. $\%$ starch) diet for 2 or 10 weeks (Table 1). The main source of fat was lard supplemented with soybean oil $(1 \%)$ in order to provide essential fatty acids (Cahova et al. 2012). This diet contains approx. $40 \%$ of saturated fatty acid, $50 \%$ of monounsaturated fatty acid (mainly oleic acid) and up to $10 \%$ polyunsaturated fatty acids (mostly linoleic acid). A balanced composition of all necessary nutrients was ensured by the use of dried milk and yeast together with casein as the source of protein. The animals designed as "fasted" were deprived of food for $16 \mathrm{hrs}$ prior the experiment. All experiments were performed in agreement with the Animal Protection Law of the Czech Republic 311/1997 and were approved by the ethical committee of Institute for Clinical and Experimental Medicine.

\section{Determination of autophagy flux}

Our assay is based on the method described by Haspel et al. (2011) with significant modification. Fasted rats underwent a partial hepatectomy. Through an 
Table 1. Composition of the diets. The content of the macronutrients is given in weight to weight percent.

\begin{tabular}{lccc}
\hline MACRONUTRIENTS & & & \\
\hline & w.w. & SD & HF \\
\hline Crude protein & $\%$ & 22 & 14 \\
Fat & $\%$ & 3 & 33 \\
Fiber & $\%$ & 3 & 3 \\
Ash & $\%$ & 5.5 & - \\
Starch & $\%$ & 68 & 17 \\
\hline
\end{tabular}

\section{MINERALS \& VITAMINS}

\begin{tabular}{lccc}
\hline Cu & $\mathrm{mg} / \mathrm{kg}$ & 25 & 25 \\
Vitamin A & $I U / \mathrm{kg}$ & 30 & 30 \\
Vitamin D3 & $\mu g / \mathrm{kg}$ & 3 & 3 \\
Vitamin E & $\mathrm{mg} / \mathrm{kg}$ & 120 & 200 \\
Vitamin C & $\mathrm{mg} / \mathrm{kg}$ & 120 & 120 \\
Vitamin PP & $\mathrm{mg} / \mathrm{kg}$ & 36 & 36 \\
Vitamin B1 & $\mathrm{mg} / \mathrm{kg}$ & 2.8 & 2.8 \\
Vitamni B2 & $\mathrm{mg} / \mathrm{kg}$ & 3.2 & 3.2 \\
Vitamin B6 & $\mathrm{mg} / \mathrm{kg}$ & 4 & 4 \\
Calcium pantothenate & $\mathrm{mg} / \mathrm{kg}$ & 13.2 & 13.2 \\
\hline
\end{tabular}

incision of mid-abdomen wall under general isoflurane anaesthesia, the median and left lateral lobes of the liver were ligated and then resected (Higgins and Anderson 1931). This piece of liver was marked as sample A and was immediately frozen in liquid nitrogen. The abdominal cavity was closed and chloroquine $(120 \mathrm{mg} / \mathrm{kg}$ b.wt.) was administered intraperitoneally in order to inhibit lysosomal activity in the liver. Rats were terminated by exsanguination from abdominal aorta $4 \mathrm{hrs}$ later. We visually checked the abdominal cavity and we did not observe any significant bleeding. We removed the rest of liver that was marked as sample B and was dissected and immediately frozen in liquid nitrogen. Samples of tissue were stored in $-40{ }^{\circ} \mathrm{C}$ until processing. Autophagy intensity was assessed as the accumulation of autophagy marker LC3-II in chloroquine-treated samples.

The isoflurane anaesthesia was employed as it is well tolerated by the animals fed a 10 week high fat diet exhibiting severe steatosis. This type of anaesthesia is associated with a significant decrease by serum FFA concentration which is the consequence of the inhibitory effect of isoflurane on isoproterenol-stimulated lipolysis in adipose tissue (Prokocimer et al. 1987). We found no information indicating any effect of isoflurane on liver lysosomal lipase.

\section{Separation and immunodetection of proteins}

The liver homogenate $(20 \% \mathrm{wt} / \mathrm{vol})$ was prepared by homogenisation of fresh liver tissue (part of sample A) in $0.25 \mathrm{M}$ sucrose; $0.001 \mathrm{M}$ EDTA $\mathrm{pH}=7.4$; heparin $7 \mathrm{IU} / \mathrm{m}, 1 \mathrm{mM}$ PMSF, leupeptin $10 \mu \mathrm{g} / \mathrm{ml}$, aprotinin $10 \mu \mathrm{g} / \mathrm{ml}$ by Teflon pestle homogeniser. The crude impurities were removed by brief centrifugation at $850 \mathrm{~g}$. Fat cake and all traces of the fat remaining on the tube wall were carefully removed in order to prevent contamination of the homogenate. Proteins in fraction were separated by SDS-PAGE and the protein of interest was recognised by specific antibody. LAL content was determined in $20 \%$ homogenate and recognised with mouse monoclonal [9G7F12] to lysosomal acid lipase, Abcam, Cambridge, UK. LC3-II content was determined in $20 \%$ liver homogenate lyses by $2 \%$ SDS at $100{ }^{\circ} \mathrm{C}$. $\mathrm{LC} 3$ in the lysates was recognised with rabbit polyclonal to LC3A/B (Abcam, Cambridge, UK). LC3-I and LC3-II were distinguished by difference and molecular weight (18 and $16 \mathrm{kDa}$ ). The bands were visualised using ECL and quantified using FUJI LAS-3000 imager (FUJI FILM, Japan).

Assay of lysosomal lipase activity

$4 \%$ homogenate prepared from fresh tissue under isosmotic conditions (250 mM sucrose) were used for the assay. The reaction medium $\left(92.5 \mathrm{kBq}{ }^{3} \mathrm{H}\right.$ triolein, $100 \mu \mathrm{M}$ cold triolein, $110 \mu \mathrm{M}$ lecithin, $0.15 \mathrm{M} \mathrm{NaCl}$ ) was emulsified by sonification (Hielsler ultrasonic homogeniser UP200S, Teltow, Germany) in $0.1 \mathrm{M}$ acetate buffer $(\mathrm{pH}=4.5)$ containing $6 \% \mathrm{BSA}$ free fatty acids. The assay itself was performed under hypoosmotic conditions in order to ensure the release of the enzyme sequestered within the lysosomes. The substrate was incubated with the enzyme for $60 \mathrm{~min}$ at $30^{\circ} \mathrm{C}$. The released fatty acids were extracted according to Belfrage and Vaughan (1969) and counted for radioactivity.

Determination of glucuronidase and acid phosphatase activities

Enzyme activities were determined in $20 \%$ homogenate diluted in saline and $0.1 \mathrm{M}$ acetate buffer $(\mathrm{pH}=4.5)$. Glucuronidase (GU) (EC 3.2.1.31) activity was assayed according to Koldovský and Palmieri (1971). The activity of acid phosphatase (AP) (EC 3.1.3.2) was determined employing Acid Phosphatase Assay Kit (Sigma Aldrich, Saint Louis, USA). 


\section{Triglyceride content in tissues}

Lipids were extracted from $1 \mathrm{~g}$ of fresh tissue homogenised in $4 \mathrm{ml}$ of $\mathrm{H}_{2} \mathrm{O} .1 \mathrm{ml}$ of the homogenate was extracted in $15 \mathrm{ml}$ of 2:1 chloroform : methanol for 24 hours. The organic and aqueous phases were removed

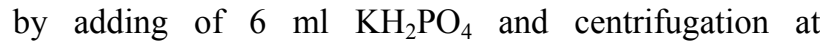
$3000 \mathrm{rpm}$ for $20 \mathrm{~min}$. $1 \mathrm{ml}$ of the organic phase was completely dried, resuspended in $100 \mu \mathrm{l}$ of isopropylalcohol and $10 \mu \mathrm{l}$ were used for the analysis. The triglyceride concentration in this aliquot was determined using commercially available kit (PlivaLachema Diagnostics, Czech Republic).

\section{Real-time RT-PCR}

The samples of liver tissue (sample A) were dissected immediately after decapitation and frozen in liquid nitrogen. Total-RNA was extracted from tissue samples using Trizol reagent (Invitrogen) according to standard protocol as described previously (Brinkhof et al. 2006). A DNAase step was included to avoid possible DNA contamination. The standard amount of total RNA
(500 ng) was used to synthesise the first-strand cDNA (High Capacity RNA-to-cDNA kit, Applied Biosystems, Foster City, CA). No template control was included in the test for contamination. RT-PCR amplification mixtures $(25 \mu \mathrm{l})$ contained $1 \mu \mathrm{l}$ template cDNA, SYBER Green master mix buffer (Quanti-Tect, Qiagen, Hilden) and $400 \mathrm{nM}(10 \mathrm{pmol} /$ reaction) forward and reverse primer (Table 2). Reactions were run on Applera $7300 \mathrm{H}$ Fast Real-Time PCR detector (Applied Biosystems). The results were analysed by SDS software vs. 2.3 (Applied Biosystems). All primers were designed using Primer3 software. The expression of genes of interest was normalised to the housekeeper gene beta-2 microtubulin (B2M) and calculated using $\Delta \Delta \mathrm{Ct}$ method.

\section{Statistic analysis}

Date are presented as mean \pm SEM. Statistical analysis was performed using Kruskal-Wallis test with multiple comparison $(\mathrm{n}=5-7)$. Differences were considered statistically significant at the level of $\mathrm{p}<0.05$.

Table 2. Primer characteristics.

\begin{tabular}{|c|c|c|c|}
\hline Gen & $\begin{array}{c}\text { NCBI } \\
\text { Ref. Sequence }\end{array}$ & Left primer & Right primer \\
\hline Glucuronidase & NM_017015.2 & CGAACCAGTCACCACTGAGAG & ATTGTGAACGGTCTGCTTCC \\
\hline Acid phosphatase & NM_016988.1 & CTGCAGACACAGAGGTGATTG & TTTGGGCGTAGGTAATCAGG \\
\hline Lysosomal lipase & NM_012823.1 & CAATCAGAGTTATCCACCCTTG & CCACAAGAACATTCCCGAGT \\
\hline $\begin{array}{l}\text { Beta-2 } \\
\text { microglobulin }\end{array}$ & NC_005102.2 & ATTCAGAAAACTCCCCAAATTC & AAAGACCAGTCCTTGCTGAAG \\
\hline
\end{tabular}

Table 3. Characteristics of experimental groups.

\begin{tabular}{|c|c|c|c|c|}
\hline & & SD & HF-2 & HF-10 \\
\hline Body weight (g)-14 wks & & $305 \pm 5$ & $309 \pm 5$ & $299 \pm 4$ \\
\hline Body weight (g)-16 wks & & $343 \pm 6$ & $359 \pm 7$ & $327 \pm 4$ \\
\hline Body weight (g)-24 wks & & $415 \pm 9$ & - & $402 \pm 8$ \\
\hline Adiposity $(g)$ & fasting & $1.2 \pm 0.11$ & $1.4 \pm 0.04$ & $2 \pm 0.08^{\# \# \#}$ \\
\hline s-glucose (mmol/l) & fasting & $6.3 \pm 0.2$ & $7.4 \pm 0.2^{* *}$ & $7.4 \pm 0.1^{\# \#}$ \\
\hline s-insulin $(n g / l)$ & fasting & $112 \pm 9$ & $121 \pm 6$ & $165 \pm 10^{\# \#}$ \\
\hline $\mathrm{s}-T A G(\mathrm{mmol} / \mathrm{l})$ & fasting & $2.3 \pm 0.7$ & $3.1 \pm 0.4$ & $3 \pm 0.4$ \\
\hline \multirow{2}{*}{$\beta$-hydroxybutyrate $(\mu \mathrm{mol} / \mathrm{l})$} & fasting & $1.8 \pm 0.1$ & $3.6 \pm 0.14^{* * *}$ & $2.4 \pm 0.2^{\#}$ \\
\hline & fed & $0.1 \pm 0.04$ & $0.48 \pm 0.03^{* * *}$ & $0.5 \pm 0.09^{\# \# \#}$ \\
\hline Liver TAG ( $\mu \mathrm{mol} / \mathrm{g} w . w t)$. & fasting & $10.8 \pm 2.0$ & $39.6 \pm 6.0^{* * *}$ & $50.6 \pm 9.6^{\# \#}$ \\
\hline
\end{tabular}

Adiposity was expressed as weight of epididymal fat pad per 100 grams body weight. Results are shown as mean \pm SEM, $n=6-10$. ${ }^{* *} \mathrm{p}<0.01,{ }^{* * *} \mathrm{p}<0.001 \mathrm{HF}-2$ vs. SD, ${ }^{\#} \mathrm{p}<0.05,{ }^{\# \#} \mathrm{p}<0.01,{ }^{\# \# \#} \mathrm{p}<0.001 \mathrm{HF}-10$ vs. SD 


\section{Results}

\section{Characteristics of experimental groups}

We found no difference in body weight among experimental groups (Table 3 ). The adiposity (expressed as weight of epididymal fat pad per 100 grams body weight) was similar in SD and HF-2 but significantly higher in HF-10. Fasting glycaemia was elevated in both HF-2 and HF-10 groups but hyperinsulinemia was proved only in HF-10. The alterations in glucose metabolism were not accompanied by fasting hypertriglyceridemia. The increased fat utilisation for energy production was documented by the elevation of $\beta$-hydroxybutyrate content in serum in HF-2 and HF-10 animals. Interestingly, ketogenesis in fasting is lower in HF-10 compared with HF-2 group ( $\mathrm{P}=0.035)$ which suggests a tendency to the attenuation of TAG utilisation in the liver. As expected, compared with the SD group, the HF diet administered animals accumulated an increased amount of TAG in the liver depending on the length of diet administration.

\section{Effect of high fat diet on autophagy flux}

The aim of our experiment was to evaluate the effect of a high fat diet on the autophagy flux, which we determined as the change of the amount of the autophago(lyso)somal membrane marker LC3-II before and after chloroquine treatment in vivo. The difference in LC3-II content before and after chloroquine treatment could be interpreted as the rate of LC3-II formation and may thus serve as the indicator of autophagy intensity. The results are shown in Figure 1. The autophagy flux was significantly elevated in HF-2 compared with SD group. In contrast, no autophagy flux was detected in HF10 group. Taken together, these results indicate that short- and long-term lasting steatosis has opposite effects on autophagy in the liver, the latter leading to its profound impairment.
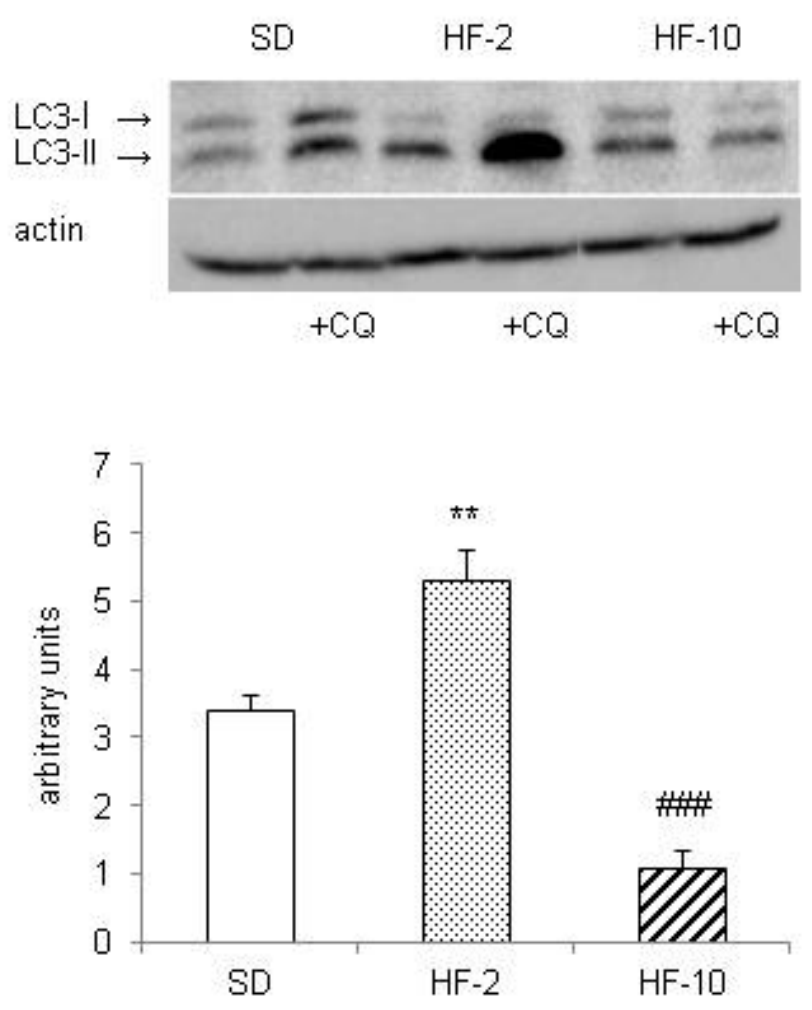

Fig. 1. Effect of HF diet on autophagy intensity. Fasted animals in isoflurane narcosis were subjected to the partial hepatectomy and sample of liver tissue (A) was immediately frozen in liquid nitrogen. Lysosomal activity was inhibited by chloroquine $(120 \mathrm{mg} / \mathrm{kg}$ b.wt., i.p.). The experiment was terminated $4 \mathrm{hrs}$ later and the liver tissue sample B was dissected and frozen. Autophagy flux was assessed as the accumulation of autophagy marker LC3-II in chloroquine-treated samples. Results are expressed as the ratio of LC3-II post- (B) and pre- (A) chloroquine treatment; given as mean \pm S.E.M., $n=6 .{ }^{* *} p<0.01$ HF-2 vs. SD; ${ }^{\# \# ~} \mathrm{p}<0.005$ HF-10 vs. SD

Table 4. mRNA expression of selected autophagy markers and lysosomal enzymes.

\begin{tabular}{|c|c|c|c|c|}
\hline & & SD & HF-2 & HF-10 \\
\hline Autophagy & Beclin & 1 & $1.26 \pm 0.06^{*}$ & $1 \pm 0.03$ \\
\hline markers & Atg 16 & 1 & $1.45 \pm 0.04^{* *}$ & $0.63 \pm 0.15^{\#}$ \\
\hline \multirow{3}{*}{$\begin{array}{l}\text { Lysosomal } \\
\text { enzymes }\end{array}$} & Lysosomal lipase & 1 & $0.9 \pm 0.04$ & $1 \pm 0.06$ \\
\hline & Glucuronidase & 1 & $1.02 \pm 0.08$ & $0.76 \pm 0.06$ \\
\hline & Acid phosphatase & 1 & $1.16 \pm 0.1$ & $0.89 \pm 0.06$ \\
\hline
\end{tabular}

mRNA was quantified by RT-PCR, with expression in standard diet (SD) arbitrary set at $1 .{ }^{*} \mathrm{p}<0.05,{ }^{* *} \mathrm{p}<0.01 \mathrm{HF}-2 \mathrm{vs}$. SD; ${ }^{*} \mathrm{p}<0.05 \mathrm{HF}-$ 10 vs. SD 
Effect of high fat diet on the expression of autophagic genes

As described above, we found that a high fat diet had serious impact on autophagy flux and we were further interested if this effect is regulated at the transcriptional level. We tested the mRNA expression of two autophagy markers, Beclin 1 and Atg 16 (Table 4). The former is implicated in the proximal part of autophagy pathway and initiates the formation of phagophore, the latter is important for modification the nascent autophagosomal membrane and it is involved in the lipidation of LC3 protein and in the translocation of LC3-II into the autophagosomal membrane. We found small but significant increase in the expression of beclin $(\mathrm{P}=0.048)$ and more pronounced increase in the expression of Atg $16(\mathrm{P}=0.015)$ in $\mathrm{HF}-2$ group which indicates that the rise in autophagy is reflected also at the transcriptional level. In rats fed HF diet for 10 weeks (HF-10), the expression of beclin returned to the normal level and the Atg16 expression was significantly downregulated. This data indicates that HF diet induced changes in autophagy flux are, at least partly, mediated also at the mRNA transcription level.

Effect of high fat diet on the activity and expression of lysosomal enzymes

The availability of lysosomal enzymes represents the necessary condition of successful degradation of material via autophagy-lysosomal pathway. At first, we focused on the effect of high fat diet on the activity and expression of an enzyme responsible for TAG degradation in lysosomes, lysosomal lipase. We found that the total activity of lysosomal lipase is similar in SD and HF-2 groups, but that it is significantly elevated in HF-10 (Figure 2A). The expression of LAL protein followed a partly different pattern. After 2 weeks of HF diet feeding, LAL protein content was significantly diminished compared with the SD group (Figure 3). In contrast, long-term HF diet administration resulted in the significant increase of LAL protein detected in liver homogenate.

We further determined the activities of two other enzymes generally accepted as lysosomal markers (glucuronidase, acid phosphatase). We observed no uniform trend in the influence of the HF diet on their activities due to short- or long-term diet administration. The activity of glucuronidase was attenuated in HF-2 compared with HF-10 and SD groups (Figure 2B) while the activity of acid phosphatase was unaffected in HF-2 and elevated in HF-10 group (Figure 2C).

The mRNA expression of any of the three lysosomal enzymes tested (LAL, GU, AP) was not affected by the length of HF diet administration and was not different from the SD group (Table 4).

A

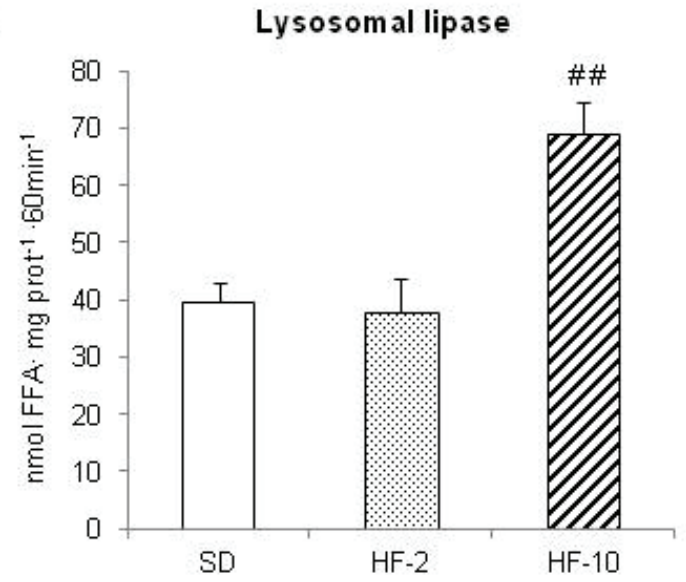

B

Glucuronidase

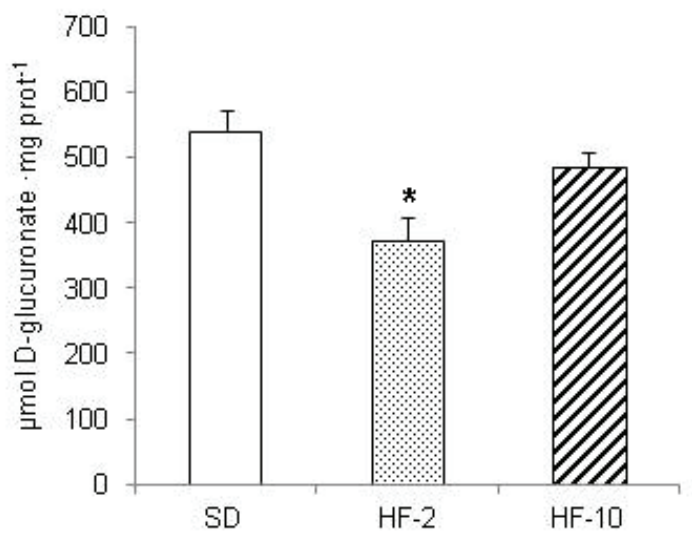

C

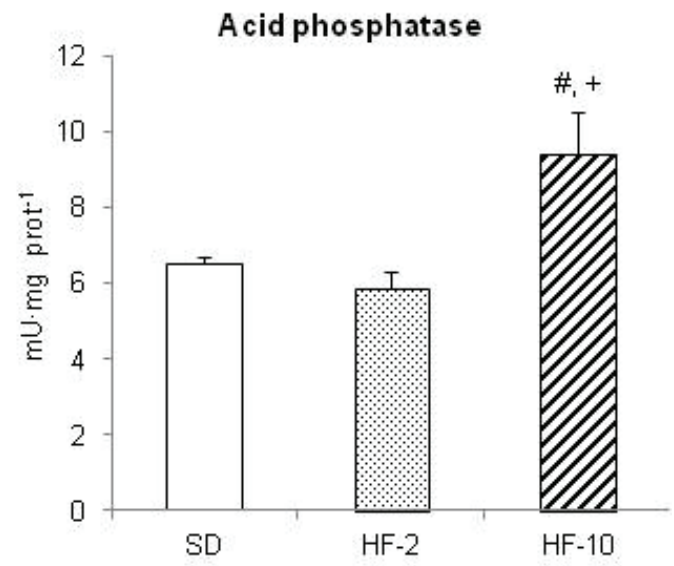

Fig. 2. Effect of HF diet on lysosomal enzymes activities. A: lysosomal lipase, B: glucuronidase, C: acid phosphatase. The enzyme activities were determined in liver homogenates prepared from sample $A$ (i.e. before chloroquine treatment). Results are shown as arithmetic mean \pm SEM, $n=6 .{ }^{*} p<0.05$ HF-2 vs. SD, ${ }^{\#} p<0.05{ }^{\# \#} p<0.01$ HF-10 vs. SD, ${ }^{+} p<0.05$ HF- 10 vs. HF- 2 

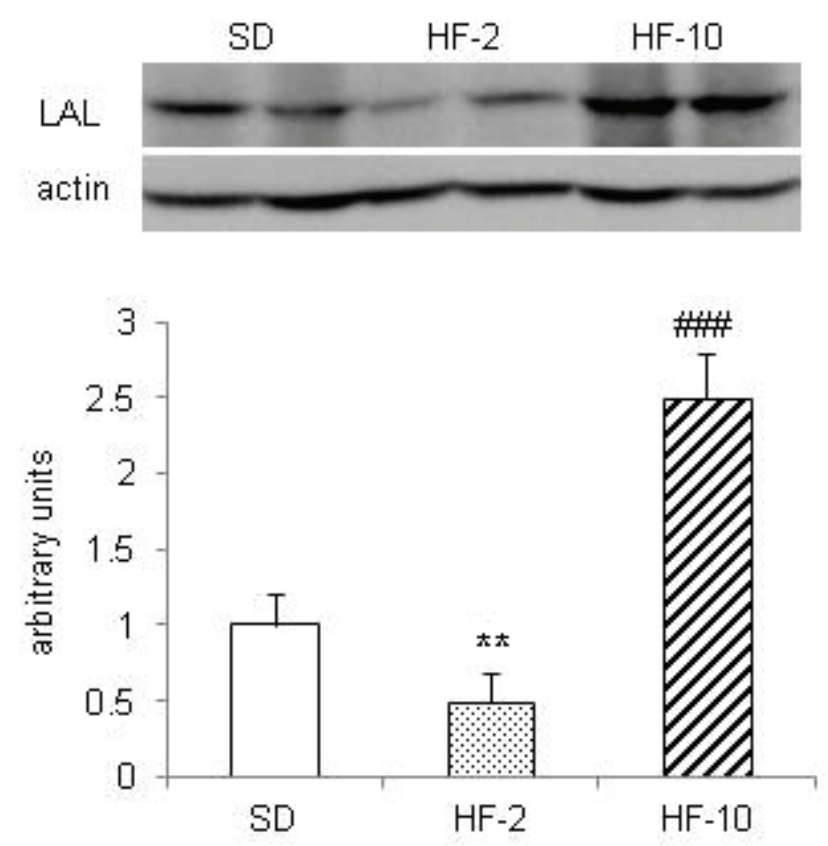

Fig. 3. Effect of HF diet on lysosomal lipase protein content in homogenate. Results are expressed as mean \pm S.E.M., $n=6$. ${ }^{* *} p<0.01$ HF-2 vs. SD; ${ }^{\# \# \#} p<0.005$ HF-10 vs. SD

\section{Discussion}

In this study, we bring the evidence that the intensity of autophagy-lysosomal pathway depends on the TAG liver content and on the duration of steatosis. Our data further suggests that in response to HF diet administration, autophagy flux itself and lysosomal enzymes expressions are regulated independently. Our conclusions are based on following findings: 1) the autophagy response to HF diet is biphasic - two weeks of HF administration resulted in the increased autophagy flux in the liver while the long-term HF feeding led to its significant attenuation; 2) total activity of lysosomal enzyme responsible for TAG degradation, LAL, was increasing along with the duration of HF administration and TAG liver accumulation; 3 ) the total activity of two other lysosomal enzymes was not uniformly influenced by HF diet. These results indicate that the regulation of the whole autophagy-lysosomal pathway in response to the increased supply of dietary fat occurs at the proximal step (autophagy flux).

The TAG metabolism in the liver is subject to a highly sensitive regulation in order to fulfil the actual needs of the organism. It has been shown that the liver is a site of continuous lipolysis of endogenous TAG stored in the form of cytosolic lipid droplets. The released FFA's are used for oxidation, VLDL synthesis or are re- esterified back to the intracellular lipid storage pool (Lankester et al. 1998). This process must be carefully regulated as the insufficient lipolysis may lead to an energy substrate shortage while an excessive one may result in the production of surplus potentially toxic intermediates of lipid metabolism. There are some hints that steatosis is associated with the impairment of autophagy function (Singh et al. 2009) but exact experimental proof is still lacking.

This task is complicated by the difficulties associated with the in vivo quantification of the intensity of autophagy flux. Cellular LC3-II levels correlate with numbers of autophago(lyso)somes in cells at a snapshot in time. LC3-II measured in this way rise: a) if there is enhanced autophagosome synthesis or b) if there is a block in LC3-II degradation. Likewise, decreased snapshot levels of LC3-II can be associated with a drop in autophagosome formation but can also occur when autophagy flux, including lysosomal degradation, is induced (Rubinsztein et al. 2009). In order to overcome this problem, LC3-II protein must be measured in the presence of lysosomal activity inhibitor, i.e. chloroquine, which prevents LC3-II degradation in lysosome. We modified a standard in vitro method for measuring of autophagic flux in vivo using chloroqiune assay. In our experimental setting, the animals were subjected to partial hepatectomy to obtain a sample of unaffected liver tissue. Then chloroquine was then applied i.p. and the intra-abdominal organs were exposed to this lysomotropic agent. Autophagy flux intensity was assessed as the accumulation of autophagy marker LC3-II in chloroquine-treated vs. untreated samples from the same animal. The data presented in Fig. 1 show the importance of this approach. If only the untreated samples were evaluated, then the conclusion would be that autophagy is comparably stimulated both after shortand long-term HF diet feeding. Nevertheless, the determination of autophagy flow revealed that autophagy is actually stimulated only in HF-2 group while in HF-10 is substantially diminished.

Our results showed that in the liver the autophagic response to the increased fat supply in the diet is biphasic. At the beginning, autophagy flux is stimulated. We speculate that this transitional increase of autophagy may represent an adaptive mechanism in order to get rid of the fat overload. The total activity of lysosomal lipase, lysosomal TAG degrading enzyme, was comparable with SD fed animals but as we have previously shown, a short-term HF diet is associated with 
a significant translocation of LAL activity as well as LAL protein into autophagolysomal fraction enriched with TAG and with increased formation of TAG degradation products (Cahova et al. 2012). Rather surprisingly, total LAL protein content was decreased in the HF-2 group. We explain this discrepancy by the accentuated degradation of the enzyme in activated autophagolysosomes. The total LAL amount present in the cell exceeds several times the amount of the enzyme actually active so the degraded enzyme could be easily replenished from the inactive stores. The effect of longterm HF diet was quite opposite. In the liver of rats fed HF diet for 10 weeks, the autophagy flux was nearly completely impaired. In contrast, the activities (measured on artificial substrate under optimal conditions) of lysosomal enzymes LAL and AP were significantly higher than in the SD group and the GU activity was comparable. We suppose that this observation could be explained by their significantly attenuated degradation in lysosomes that are not activated by autophagy. In accordance with this hypothesis, we observed an elevation of LAL protein content in HF-10 group.

In the liver of animals chronically fed the highfat diet, the autophagy could be down-regulated by several mechanisms. First, it has been reported that expression of some key autophagy genes (vps34, atg12, and gabarapl1) were suppressed in the presence of insulin resistance and hyperinsulinemia via FoxO1dependent pathway (Liu et al. 2009). Second, one of the most important cellular inhibitors of autophagy is mTOR kinase which serves as a cellular sensor of nutrients. Data coming from several groups revealed that mTOR is chronically activated in the liver of high-fat diet administered mice (Korsheninnikova et al. 2006, Wang et al. 2010). And finally, Koga et al. (2010) showed that macroautophagy failure induced by chronic lipid challenge or acute exposure to abnormally high lipid concentrations may be caused by the reduced fusion ability between autophagosomes and lysosomes.

In general, the attenuation of autophagy is considered to be deleterious as it may render cells particularly susceptible to stressors, such as oxidative stress, because of the inability to handle the damage associated with these stressors (Rodriguez-Navarro et al. 2012). Nevertheless, in this particular condition, the down-regulation of autophagy may also represent a sort of "protective" mechanism. It has been previously reported that LAL is capable of hydrolysing triacylglycerols and that the dominant products of its action on TAG molecule are diacylglycerol (DAG) and one molecule of fatty acid (Hayase and Tappel 1970). DAG is a known activator of several protein kinase $\mathrm{C}$ (PKC) isoforms of including PKC $\varepsilon$ which was delineated a specific role in the development of fat-induced insulin resistance in the liver (Samuel et al. 2004, Samuel et al. 2007). We have previously shown that short-term HFDinduced TAG accumulation in the liver is associated with the elevated DAG production by LAL and rapid onset of hepatic IR via the PKCE activation (Cahova et al. 2012). From this point of view, the down-regulation of autophagy-lysosomal pathway in steatosis may represent a protective mechanism against the increased formation of potentially deleterious lipid metabolism intermediates.

\section{Conflict of Interest}

There is no conflict of interest.

\section{Acknowledgements}

This work was supported by the institutional financial support of the Institute for Clinical and Experimental Medicine (MZO 00023001) and by grant no. P301/11/2418 from GA AV CR.

\section{References}

BELFRAGE P, VAUGHAN M: Simple liquid-liquid partition system for isolation of labeled oleic acid from mixtures with glycerides. J Lipid Res 10: 341-344, 1969.

BRINKHOF B, SPEE B, ROTHUIZEN J, PENNING LC: Development and evaluation of canine reference genes for accurate quantification of gene expression. Anal Biochem 356: 36-43, 2006.

CAHOVA M, DANKOVA H, PALENICKOVA E, PAPACKOVA Z, KOMERS R, ZDYCHOVA J, STICOVA E, KAZDOVA L: The increased activity of liver lysosomal lipase in nonalcoholic fatty liver disease contributes to the development of hepatic insulin resistance. Biochem Res Int 2012: 135723, 2012.

CAO Y, KLIONSKY DJ: Physiological functions of Atg6/Beclin 1: a unique autophagy-related protein. Cell Res 17: 839-849, 2007.

De DUVE C, WATTIAUX R: Functions of lysosomes. Annu Rev Physiol 28: 435-492, 1966. 
FINN PF, DICE JF: Proteolytic and lipolytic responses to starvation. Nutrition 22: 830-844, 2006.

GORDON PB, HOYVIK H, SEGLEN PO: Prelysosomal and lysosomal connections between autophagy and endocytosis. Biochem J 283: 361-369, 1992.

HASPEL J, SHAIK RS, IFEDIGBO E, NAKAHIRA K, DOLINAY T, ENGLERT JA, CHOI AM: Characterization of macroautophagic flux in vivo using a leupeptin-based assay. Autophagy 7: 629-642, 2011.

HAYASE K, TAPPEL AL: Specificity and other properties of lysosomal lipase of rat liver. J Biol Chem 245: 169-175, 1970.

HIGGINS GM, ANDERSON RM: Experimental pathology of the liver: restoration of the following partial hepatectomy. Arch Pathol 12: 186-202, 1931.

JAGER S, BUCCI C, TANIDA I, UENO T, KOMINAMI E, SAFTIG P, ESKELINEN EL: Role for Rab7 in maturation of late autophagic vacuoles. J Cell Sci 117: 4837-4848, 2004.

JUNG CH, JUN CB, RO SH, KIM YM, OTTO NM, CAO J, KUNDU M, KIM DH: ULK-Atg13-FIP200 complexes mediate mTOR signaling to the autophagy machinery. Mol Biol Cell 20: 1992-2003, 2009.

KLIONSKY DJ, ABELIOVICH H, AGOSTINIS P, AGRAWAL DK, ALIEV G, ASKEW DS, BABA M, ET AL.: Guidelines for the use and interpretation of assays for monitoring autophagy in higher eukaryotes. Autophagy 4: 151-175, 2008.

KOGA H, KAUSHIK S, CUERVO AM: Inhibitory effect of intracellular lipid load on macroautophagy. Autophagy 6 : 825-827, 2010.

KOLDOVSKÝ O, PALMIERI M: Cortisone-evoked decrease of acid- $\beta$-galactosidase, $\beta$-glucuronidase, $N$-acetyl- $\beta$ glucosaminidase and arylsulphatase in the ileum of suckling rats. Biochem J 125: 697-701, 1971.

KORSHENINNIKOVA E, VAN DER ZON GC, VOSHOL PJ, JANSSEN GM, HAVEKES LM, GREFHORST A, KUIPERS F, REIJNGOUD DJ, ROMIJN JA, OUWENS DM, MAASSEN JA: Sustained activation of the mammalian target of rapamycin nutrient sensing pathway is associated with hepatic insulin resistance, but not with steatosis, in mice. Diabetologia 49: 3049-3057, 2006.

LANKESTER DL, BROWN AM, ZAMMIT VA: Use of cytosolic triacylglycerol hydrolysis products and of exogenous fatty acid for the synthesis of triacylglycerol secreted by cultured rat hepatocytes. $J$ Lipid Res 39: 1889-1895, 1998.

LEVINE B, KROEMER G: Autophagy in the pathogenesis of disease. Cell 132: 27-42, 2008.

LIU HY, YEHUDA-SHNAIDMAN E, HONG T, HAN J, PI J, LIU Z, CAO W: Prolonged exposure to insulin suppresses mitochondrial production in primary hepatocytes. J Biol Chem 284: 14087-14095, 2009.

MIZUSHIMA N, LEVINE B, CUERVO AM, KLIONSKY DJ: Autophagy fights disease through cellular selfdigestion. Nature 451: 1069-1075, 2008.

PROKOCIMER PG, MAZE M, HOFFMAN BB: Role of the sympathetic nervous system in the maintenance of hypertension in rats harboring pheochromocytoma. J Pharmacol Exp Ther 241: 870-874, 1987.

RODRIGUEZ-NAVARRO JA, KAUSHIK S, KOGA H, DALL'ARMI C, SHUI G, WENK MR, Di PAOLO G, CUERVO AM: Inhibitory effect of dietary lipids on chaperone-mediated autophagy. Proc Natl Acad Sci U S A 109: E705-E714, 2012.

RUBINSZTEIN DC, CUERVO AM, RAVIKUMAR B, SARKAR S, KOROLCHUK V, KAUSHIK S, KLIONSKY DJ: In search of an "autophagomometer". Autophagy 5: 585-589, 2009.

SAMUEL VT, LIU ZX, QU X, ELDER BD, BILZ S, BEFROY D, ROMANELLI AJ, SHULMAN GI: Mechanism of hepatic insulin resistance in non-alcoholic fatty liver disease. J Biol Chem 279: 32345-32353, 2004.

SAMUEL VT, LIU ZX, WANG A, BEDDOW SA, GEISLER JG, KAHN M, ZHANG XM, MONIA BP, BHANOT S, SHULMAN GI: Inhibition of protein kinase Cepsilon prevents hepatic insulin resistance in nonalcoholic fatty liver disease. J Clin Invest 117: 739-745, 2007.

SEGLEN PO: Their role in protein breakdown. In: Lysosomes. H GLAUMANN, FJ BALLARD (eds), Academic Press, London, 1987, pp 369-414.

SINGH R: Autophagy and regulation of lipid metabolism. Results Probl Cell Differ 52: 35-46, 2010.

SINGH R, KAUSHIK S, WANG Y, XIANG Y, NOVAK I, KOMATSU M, TANAKA K, CUERVO AM, CZAJA MJ: Autophagy regulates lipid metabolism. Nature 458: 1131-1135, 2009. 
SUZUKI K, KUBOTA Y, SEKITO T, OHSUMI Y: Hierarchy of Atg proteins in pre-autophagosomal structure organization. Genes Cells 12: 209-218, 2007.

WANG Y, SHI M, FU H, XU H, WEI J, WANG T, WANG X: Mammalian target ot the rapamycin pathway is involved in non-alcoholic fatty liver disease. Mol Med Report 3: 909-915, 2010. 